\title{
CONSTRUINDO ESPAÇOS TRANSNACIONAIS A PARTIR DOS FEMINISMOS
}

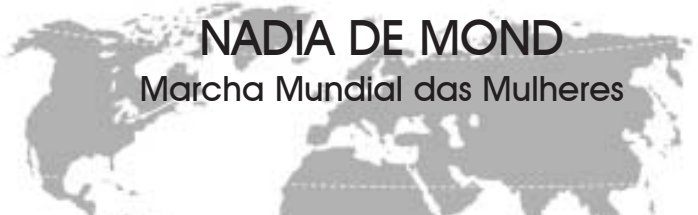

A construção de espaços transnacionais não é novidade para o feminismo. No século passado foram muitas as interconexões entre as elaborações feministas européias e as das Américas. Redes internacionais foram construídas sobre temáticas específicas - a saúde, os direitos reprodutivos, a violência...-ou com objetivos de lobby nas conferências e nas instituições transnacionais. A nossa análise do patriarcado como sistema universal de dominação foi enriquecida pelo estudo de sua articulação com os contextos econômicos e culturais mais variados e difusos pelo planeta, acabando, parando, entre outras coisas, com o mito segundo o qual a questão do patriarcado, entendido como sistema global de domínio de um sexo sobre o outro, fosse uma invenção feminista ocidental que não interessava às mulheres e sociedades do Sul.

Em particular a conferência da ONU sobre as mulheres, em Pequim, em 1995, e a relativa conferência paralela das ONGs em Huairou deram um salto de qualidade na internacionalização do feminismo e no crescimento exponencial da contribuição das mulheres do Sul para as análises feministas.

\section{A gênese da Marcha Mundial das Mulheres}

É praticamente nesse âmbito que foi lançada pela primeira vez a idéia da Marcha Mundial das Mulheres contra a violência e a pobreza, uma proposta proveniente da importante Federação das Mulheres de Quebéc (FFQ), resultado de uma mobilização de base exitosa no Canadá por "Pão e Rosas". O projeto da Marcha nasce da necessidade de ir além das palavras, das promessas contidas nas declarações oficiais dos organismos (inter)governativos que se comprometem a erradicar as discriminações e as violações de direitos humanos de que as mulheres são objeto. A não-aplicação dos planos de ação, solenemente assinados em tais ocasiões, levou uma boa parte de mulheres em nível internacional a recolocar em campo as ações de rua e as mobilizações para criar a pressão necessária - a 'massa crítica', dir-se-ia agora - para impor, na prática, as mudanças almejadas.

Em dois anos aquilo que era uma idéia se transformou em realidade. A partir dos contatos feitos em Huairou, com a ajuda da Internet e com o apoio organizativo decisivo da $F F Q$, criou-se uma rede diversificada de mais de seis mil coletivos de mulheres de 161

Copyright @ 2003 by Revista Estudos Feministas 
países reunidas em torno de uma plataforma mundial que ligava o repúdio à violência sistêmica contra as mulheres à luta contra o empobrecimento das mulheres. O mesmo espírito que soprava em Seattle se fazia sentir nesse movimento feminista internacional: a consciência de que só uma guinada radical nas políticas econômicas, sociais e ambientais poderia garantir a sobrevivência do planeta e garantir o respeito dos direitos humanos básicos - a partir do direito a matar a fome e de salvaguarda da integridade física - para TODOS os seres humanos; a urgência de vincular as lutas e resistências locais contra as políticas neoliberais e um projeto de alternativa global; a vontade de recolocar-se em movimento em primeira pessoa, sem delegação, para barrar a lógica mortal do pensamento único.

A estrutura flexível, mas ao mesmo tempo funcional à realização de uma campanha unitária em nível mundial, permitiu à Marcha experimentar novas formas de organização, de decisão e de gestão da diversidade.

A auto-organização e o autofinanciamento das coordenações nacionais, além de sua ampla autonomia político-organizativa (no interior de um quadro dado nos momentos de coordenações mundiais), consentiram relações de troca e parceria entre as componentes do Norte e do Sul dessa rede. Não se trata, de fato, de uma rede de solidariedade das mulheres do Norte para com as do Sul, mas de movimentos que se vinculam porque lutam, em suas casas, contra uma trama de sistemas globalizados e suas conseqüências na vida cotidiana das mulheres. A tendência ao empobrecimento feminino é universal, ainda que os pontos de partida - em termos de bem-estar econômico e acesso a serviços - sejam obviamente diferentes segundo a disposição geográfica e social ocupada por cada uma.

A tendência ao crescimento da violência contra as mulheres, em termos políticos (durante conflitos declarados) e pessoais (a violência doméstica), está documentada pelos centros de estudos e pelas operadoras dos centros antiviolência do mundo todo.

A realização da Marcha Mundial em 2000 e sua manutenção sucessiva como rede internacional evidenciou que uma verdadeira comunicação, direcionada à realização de um projeto comum, é possível nesse mundo globalizado.

Uma análise das causas profundas do empobrecimento das mulheres só poderia nos levar a evidenciar as responsabilidades políticas dos governos e das instituições internacionais: a perpetuação das dívidas do Terceiro Mundo, os planos de ajuste estrutural, os tratados de livre comércio, para citar só algumas, remetem a uma mesma lógica-a da defesa dos privilégios de uma minoria em detrimento dos interesses das populações do mundo. Uma análise detalhada das receitas de desenvolvimento do FMl e do Banco Mundial levou a Marcha Mundial das Mulheres a denunciar decididamente essas instituições como as maiores responsáveis pelas políticas de depredação dos recursos dos povos, a despeito dos adendos "por uma equidade de gênero" que inserem nesse ou naquele programa.

Nesse caminho de análise e de denúncia nos encontramos em companhia de outros movimentos, que, a partir de outros ângulos de visão, aportavam nas mesmas conclusões sobre a insustentabilidade do sistema existente. O povo de Porto Alegre estava a caminho. 


\section{Qual é a relação entre o feminismo da Marcha Mundial e o Fórum Social Mundial? Qual foi a contribuição da Marcha para o FSM?}

A Marcha Mundial das Mulheres foi uma das componentes que deram vida ao Fórum Social Mundial, fazendo com que desde o início o feminismo fosse percebido como um dos elementos indispensáveis de 'um outro mundo possível'. A consciência da própria parcialidade e da necessidade de combinar uma subjetividade múltipla de transformação da sociedade é bastante difundida no movimento dos movimentos. Mas isso não corresponde necessariamente a uma compreensão de fundo das contribuições em termos de análises, conceitos e paradigmas provenientes de sujeitos periféricos em relação à esquerda tradicional - ocidental, branca, masculina, heterossexual - que produziu um código próprio de linguagens, rituais e comportamentos supostamente universais, e perfeitamente adequados à realização de seu papel de oposição política.

Nossa relação com esse movimento é, portanto, ambivalente. Nós nos sentimos parte co-substancial dele e reconhecemos aí um espaço inédito de experimentação e confronto em função da elaboração de modelos e estratégias de transformação radical do existente. Mas, ao mesmo tempo, entramos em confronto com a inércia das formas mais subjacentes da ação políica que se traduz em barreira e obstáculos ao avanço de análises e práticas feministas, como na resistência a ceder postos de grande visibilidade e decisão a uma liderança feminina e feminista.

O feminismo introduz no movimento temas fundamentais como a releitura das estruturas econômicas através do reconhecimento e da valorização do trabalho de reprodução, que, na prática, está completamente a cargo das mulheres, e uma ótica de gênero com a qual interpretar todas as relações sociais no mundo. Sobre esses temas existe hoje uma ampla bibliografia e 'expertise' da parte de estudiosas e ativistas feministas em todos os lugares do mundo.

No plano teórico, traz conceitos fundamentais, como o da multiplicidade do sujeito da mudança (pela qual não existe uma contradição prioritária com respeito a alguma outra nem uma vanguarda única que vai dirigir o processo); a necessidade de uma abordagem holística que integre as várias esferas da vida em uma perspectiva de mudança - projeto que só pode ter sucesso quando mobiliza as energias e paixões das/os diretamente interessadas/os.

A propósito, é importante destacar a dialética entre o processo e o objetivo no sentido de que esse novo modelo de sociedade não pode ser somente um objetivo final a alcançar, mas começa a realizar-se - ou não - no processo através do qual se tenta criá lo, na escolha dos meios e dos métodos e dos objetivos imediatos, dia a dia.

Acredito que algumas práticas do movimento de mulheres, em particular da Marcha Mundial das Mulheres, são extremamente interessantes para serem estudadas, sistematizadas e generalizadas em todo o movimento. Refiro-me, por exemplo, à prática da convergência. Quero dizer convergência no sentido literal do termo - convergir/proceder na direção de um objetivo comum a partir de pontos de partida diferentes.

Essa prática pressupõe que não se começa pela discriminação das participantes a priori, com base nas suas filiações políticas, culturais, identitárias, mas, pelo contrário, nos reunimos em torno de um ou mais objetivos comuns a serem realizados. Existem apenas alguns discernimentos de fundo que determinam uma escolha de campo no que diz respeito aos conteúdos - no nosso caso, sermos feministas ou combater o patriarcado ou a desigualdade homem/mulher (é claro que a formulação já denota posições diferentes ou 
articuladas, tonalidades...) e antiliberalistas e optar por um trabalho a partir da base, includente e que tenda para a ação, no que diz respeito ao método.

Isso quer dizer privilegiar sistematicamente a busca de um denominador comum: em vez de focalizar a atenção sobre as divergências - um vício profundamente enraizado na esquerda do século XX -, fazer um grande esforço no plano subjetivo para, antes de tudo, compreender o background do qual nascem as diferentes posições em debate antes de recusá-las por não serem diferentes das nossas. A propósito disso, gostaria de contar um episódio do terceiro encontro das delegadas da Marcha Mundial em que enfrentamos a espinhosa questão dos direitos das lésbicas. É bastante claro para nós, feministas européias ou norte-americanas, que não existe feminismo sem o reconhecimento da liberdade de escolha no tema da orientação sexual, que a luta contra qualquer forma de discriminação das lésbicas faz parte da luta abrangente contra o domínio patriarcal. Essa posição não resulta nada evidente para as delegadas do Oriente Médio e da África, que operam em contextos culturais, jurídicos e religiosos completamente diferentes. Basta lembrar que em oito países a homossexualidade é punida com pena de morte ou castigos pesados; em outra dezena com penas de prisão superiores a dez anos, enquanto a reclusão por períodos de um a dez anos é regra em dezenas de países africanos e asiáticos. E que a esse arranjo jurídico corresponde naturalmente uma imposição ideológica reacionária da qual até as ativistas dos movimentos progressistas não são completamente desligadas. Não somos marcianas ou supermulheres, mas pessoas que vivem em contextos precisos que condicionam seus pensamentos e sentimentos. O que fazer agora diante desse impasse? Expulsar toda a porção africana da Marcha por não ser suficientemente feminista? Ou, mais uma vez na história, em nome de um fim maior - a emancipação das mulheres nesse caso, como poderia ser a do proletariado no caso da esquerda comunista -, sacrificar as necessidades 'secundárias' em favor das 'principais'?

Nem uma coisa nem outra. A partir de uma postura de profundo respeito e uma grande vontade de aprender com as experiências reais da vida, produziu-se o 'milagre' de um verdadeiro diálogo entre posições que pareciam diametralmente opostas. Testemunhos de vida de mulheres lésbicas, em países do Sul fortemente repressivos, mandaram embora muitos dos preconceitos das mulheres das Áfricas, que por sua vez nos fizeram entender que outras necessidades primordiais, de vida ou morte, estão na ordem do dia para a massa das mulheres no campo ou nas periferias urbanas africanas, tornando difícil considerar outros problemas que não são vividos na pele, direta e cotidianamente.

Conto esse episódio para destacar como a questão da convergência não tem a ver somente (e talvez nem mesmo prioritariamente) com uma impostação intelectual, mas, sim, com uma predisposição de ânimo, uma impostação que coloca em jogo o campo da ética e da emoção. Questões que foram muito mais exploradas pelo movimento de mulheres do que pela esquerda masculina que, em vez disso, freqüentemente as considera como apolíticas e portanto irrelevantes para a transformação do mundo.

O desafio consiste em sistematizar essas práticas, fazer com que sejam percebidas e adotadas por outras componentes do movimento de modo a converter-se em práticas comuns, mainstream.

A aliança entre vários setores do movimento deve ir além da justaposição das siglas e do reconhecimento recíproco de 'cidadania' em seu interior. A marginalidade dos novos movimentos em relação aos centros de poder produziu culturas de resistência muito radicais que se exprimem também em uma vivência diferente da ação coletiva e da resistência. De que modo as formas de organização e a relação com a materialidade da vida do mundo campesino e dos movimentos que o dirigem influenciaram o modo de ser desse movimento? E a cosmovisão dos povos originários? E a crítica profunda do movimento 
lésbico e gay à normatização da sexualidade e ao doutrinamento heterossexual que nos toca intimamente a todas/os?

Porém, a questão também manda a bola de volta para o nosso campo. Quanto o movimento feminista foi capaz de levar adiante e praticar o conflito de gênero, entendido como crítica profunda a todas as formas de domínio interpessoal, derrubando o muro artificial entre as esferas pessoal e política, conjugando incansavelmente a transformação pessoal com a social e a política? Quanto conseguimos praticar entre nós formas diferentes de liderança, includentes e antiautoritárias (evitando a armadilha da simbiose e da negação das diversidades e dos conflitos)?

Essas perguntas remetem a um debate subjacente, em voga na ltália, que supõe o caráter substancialmente pacífico do movimento de mulheres. Quem afirma essa tese vê um nexo entre algumas características (supostamente) femininas e a capacidade do movimento feminista de encarnar um modelo mais humano de transformação da sociedade. As mulheres teriam mais capacidade de gerir pacificamente os conflitos, trabalhar de forma colegiada, apegar-se-iam menos às posições de poder etc.

Na minha opinião, é errado atribuir características imutáveis à 'natureza' feminina e daí tirar conclusões sobre o plano da ação social. Acredito que o ponto de partida deva ser outro: as mulheres foram excluídas (em grande parte) dos espaços de privilégio e poder em todas as sociedades e culturas historicamente determinadas; essa posição histórica comporta um estranhamento à gestão do poder e aos mecanismos de dominação em primeira pessoa (sem negar, por outro lado, os mecanismos complexos da aceitação e da cumplicidade) e determina objetivamente uma maior liberdade de posicionamento crítico global ao modelo dominante. Trata-se de uma potencialidade que, no entanto, está toda por ser preenchida. De fato, a alteridade do feminismo depende de uma escolha subjetiva, uma opção por privilegiar certas características dentro de uma identidade adquirida ou não. Para dizê-lo em palavras parcas: não acho que as mulheres sejam intrinsecamente menos violentas, mas acho que podem decidir ser assim com mais facilidade (sem infringir constrições ligadas a milênios de construção ideológica das identidades de gênero). Do mesmo modo, não acho que as mulheres tenham, de natureza própria, uma gestão mais democrática do poder, mas acredito que sua experiência histórica de exclusão dos espaços decisórios e de vítimas de um poder arbitrário e falocrático lhes permite viver na carne a necessidade da elaboração de modelos diferentes de participação e exercício do poder. Estamos, portanto, falando de um objetivo, de uma aposta, uma opção preferencial, uma construção de identidade baseada em uma escolha política, que tem suas raízes na experiência histórica existencial das mulheres. Na minha opinião, esse projeto deveria ser explicitado, colocado no centro do debate e sistematizado, buscando alianças e contaminações com outros setores do movimento antiglobalização nesse terreno.

\section{O que significa o processo do FSM para o feminismo?}

A entrada no novo milênio corresponde a uma nova fase de mobilização e de crítica ao pensamento único. Uma nova geração entrou em movimento e muitos/as daqueles/as da geração anterior que continuaram em campo interiorizaram as derrotas e superaram o trauma. Difundiu-se uma nova consciência do próprio limite entre muitos setores novos e velhos do movimento no global. Parte-se em busca de novas alianças a partir de uma postura mais pragmática e menos ideológica. Essa onda de renovação tocou também o movimento de mulheres. O feminismo não é um fenômeno destacado do resto da sociedade, mas sofre os golpes e contragolpes da história e freqüentemente se desenvolve em relação (também conflituosa) com outros movimentos sociais (de classe, de libertação anticolonial etc.). 
Particularmente, aquela parte do feminismo que combina a análise do patriarcado com uma análise de classe e de raça, e que tem como referência principal as mulheres das classes populares, reconheceu nesse movimento um aliado seu natural. Muitas garotas que se tornaram ativas no caminho de Seattle e Porto Alegre, em todo tipo de movimento misto, viram pela primeira vez com interesse a presença de um componente feminista e se interessaram por uma leitura de gênero a respeito do próprio âmbito de engajamento, descobrindo mais tarde que as contradições de sexo não estão em nada superadas e que os temas trazidos à luz pelo feminismo lhes dizem respeito diretamente. Para o feminismo, essa ponte com a nova geração tem importância vital, assim como a contribuição das mulheres vindas de outros movimentos, negro, camponês, indígena, homossexual... no enriquecimento de sua análise e ação.

A expansão do processo FSM em nível continental e regional permitiu a criação de espaços de encontro e de articulação internacional dificilmente realizáveis para o movimento de mulheres em outras circunstâncias. E esse espaço está em crescimento contínuo.

Na Europa, por exemplo, inserimos no programa do primeiro Fórum Social Europeu (FSE), em Florença, um certo número de conferências e seminários gestionados pela Marcha Mundial das Mulheres e outras redes feministas. Apesar da adoção por parte do grupo organizador de um critério de princípio de paridade de gênero em todas as intervenções, não conseguimos, nessa primeira edição, realizar completamente esse critério. Mas o FSE nos serviu para re-amarrar um monte de relações e conhecimentos com grupos feministas que operam isoladamente na Europa Ocidental e do Leste. O resultado foi o de mirar mais alto na segunda edição do FSE. O número de conferências com claro recorte feminista aumentou, e o Fórum será precedido de uma jornada inteira dedicada aos direitos das mulheres e gerida por nós. Na França, onde acontecerá o segundo FSE, a nossa jornada está chamando a atenção de setores do movimento das mulhe res, como as jovens migrantes da segunda geração que se mobilizaram contra a violência nas periferias parisienses sob a palavra de ordem "Nem putas, nem submissas" e que até agora se mostravam céticas a respeito do feminismo, considerado elitista demais e monocultural.

Na Grécia, onde o movimento feminista era extremamente fragmentado, conseguiuse criar uma coordenação nacional entre todos os coletivos e centros feministas interessados em uma ação conjunta no âmbito do processo lançado pelo FSE, que encontrou um forte eco em todos os países do Mediterrâneo. Um fenômeno semelhante se produziu na Itália e em Portugal.

Uma rede de jovens pesquisadoras e estudantes universitárias chamada NextGenderation engajou-se ativamente junto com a Marcha e outras redes locais na afirmação e na organização dessa jornada pelos direitos das mulheres em Paris. Todos esses são sinais muito encorajadores para aquela parte do feminismo que escolheu desenvolver sua ação no interior - e não exclusivamente - do processo iniciado em Porto Alegre.

Essa nova geração propõe as próprias leituras e prioridades no interior do movimento, com um enfoque sobre as interconexões existentes entre as várias contradições sociais e culturais; uma atenção particular sobre as formas de comunicação e a liderança incorporada (embodied leadership), ou seja, não neutra em termos de sexo, classe, raça e orientação sexual. Já que a revolução não está mais atrás da esquina e nem ocorreu a morte do patriarcado, essa nova geração de feministas se interessa muito mais pelo processo da transformação em si e não somente pelo seu objetivo final (entre outras coisas, ainda a definir em sua maior parte). A ação coletiva também deve ser fonte de alegria e lugar para a expressão da criatividade, assim como um investimento afetivo e intelectual. Sem 
carga passional e apelo aos valores espirituais que a sustentam, ela não poderá mobilizar por muito tempo a energia necessária para reverter a ordem existente, começando desde já a construir o novo mundo que desejamos.

\section{Conclusões}

Parece que estamos assistindo a uma dinâmica virtuosa de crescimento e renovação do feminismo em combinação com um processo impulsionado pelo FSM e que existe uma possibilidade real de integração do pensamento feminista no interior dessa nova onda de movimento que está definindo suas formas de expressão e suas alternativas de sociedade.

Trata-se de uma oportunidade, não de uma certeza. A condição indispensável para que o feminismo possa ocupar todo o seu espaço no mainstream do movimento é que mantenha e reforce seus espaços próprios de elaboração, de escolha de prioridades, que possa ancorar sua ação nas necessidades e nos desejos fundamentais da massa das mulheres e que reforce suas alianças com o conjunto do feminismo. 